\title{
Controversies in hybrid banking: attitudes of Swiss public umbilical cord blood donors toward private and public banking
}

\author{
Gwendolin Manegold • Sandrine Meyer-Monard • \\ André Tichelli · Christina Granado • \\ Irene Hösli • Carolyn Troeger
}

Received: 23 April 2010/Accepted: 12 July 2010/Published online: 24 July 2010

(C) Springer-Verlag 2010

\begin{abstract}
Purpose Umbilical cord blood (UCB) stored in public inventories has become an alternative stem cell source for allogeneic stem cell transplantation. The potential use of autologous UCB from private banks is a matter of debate. In the face of the limited resources of public inventories, a discussion on "hybrid" public and private UCB banking has evolved. We aimed to explore the attitudes of the donating parents toward public and private UCB banking. Study design and methods A standardized, anonymous questionnaire was sent to the most recent 621 public UCB donors including items regarding satisfaction with recruitment process, the need for a second consent before release of the UCB unit for stem cell transplantation, and the donors' views on public and private UCB banking. Furthermore, we asked about their views on UCB research.

Results Of the questionnaires, $48 \%$ were returned, and $16 \%$ were lost due to mail contact. Of our donors, $95 \%$ would donate to the public bank again. As much as $35 \%$ of them were convinced that public banking was useful. Whereas $27 \%$ had never heard about private UCB banking, $34 \%$ discussed both options. Nearly $70 \%$ of donors opted for public banking due to altruism and the high costs of
\end{abstract}

G. Manegold $(\bowtie) \cdot$ C. Granado · I. Hösli · C. Troeger

Department of Obstetrics and Gynecology, University Hospital

Basel, Spitalstrasse 21, 4031 Basel, Switzerland

e-mail: gmanegold@uhbs.ch

S. Meyer-Monard

Hematology Unit, Central Institute of the Valais Hospitals,

Sion, Switzerland

A. Tichelli

Department of Hematology, University Hospital Basel,

Spitalstrasse 21, 4031 Basel, Switzerland private banking. Of our public UCB donors, $81 \%$ stated that they did not need a re-consent before UCB release for stem cell transplantation. In case of sample rejection, 53.5\% wanted to know details about the particular research project. A total of $9 \%$ would not consent.

Conclusions Almost all donors would choose public banking again due to altruism and the high costs of private banking. Shortly after donation, mail contact with former UCB donors was difficult. This might be a relevant issue in any sequential hybrid banking.

Keywords Umbilical cord blood P Public banking . Private banking $\cdot$ Hybrid banking Attitudes .

Stem cell research

\section{Introduction}

Umbilical cord blood (UCB) is an accepted stem cell source for allogeneic stem cell transplantation in the treatment of various malignant and non-malignant diseases in children and adults [1]. Thus, the demand for UCB transplants is increasing continuously. At present, more than 2,000 UCB units from both Swiss public banks (Basel and Geneva) have been registered and distributed by the Swiss Blood Stem Cell (SBSC) registry. The delivery of UCB units has steadily increased from 0 in 1997 to 11 in 2007, reflecting the above-mentioned trend (Fig. 1). Since the costs for sampling, processing and storage are currently covered by either philanthropic donors or public services, the resulting limited resources and therewith logistics are one major reason for a rather low banking rate [2].

On the other hand, private institutions are now available throughout most industrialized countries and provide their services to store UCB for a potential later autologous use. 


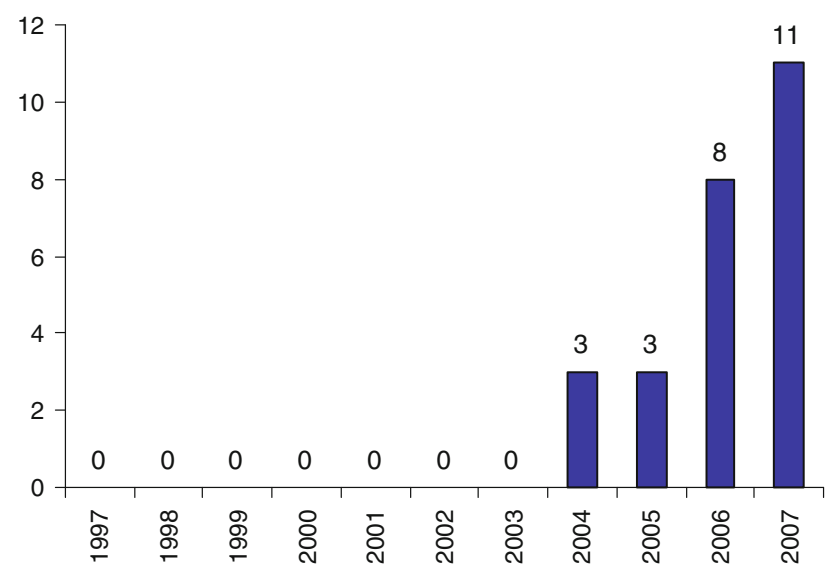

Fig. 1 Number of UCB units delivered per year by SBSC from 1997 to 2007

Advertisement is made for use in tissue regeneration in conditions such as diabetes and Parkinson's disease, as well as for the treatment of malignant hematologic diseases. True clinical applications, however, are still very speculative [3]. In contrast to public UCB banking, the costs are solely covered by the parents and therefore the donor and the family possess the UCB unit.

Currently, about 300,000 UCB units have been stored and are available for immediate use through the international stem cell registries. They provide stem cell transplants with rare HLA alleles and haplotypes that are scarcely found in bone marrow registries [4]. However, far more UCB units have been stored in private institutions. Of about 800,000 UCB units stored in private banks, clinical application such as autologous transplantations have been reported only in few cases [5]. Even less information exists on whether the stored samples meet the generally accepted quality criteria, or if rare HLA types are also more frequent in these inventories.

More recently, combined "hybrid" public and private UCB banking has emerged due to the limited funding for public UCB banks in most countries. Since resources are limited to the collection, processing and storage of good quality UCB units from all delivered infants, it is reasonable to consider new business models and combined public and private UCB banking, thus meeting the demands for UCB stem cells in general [2]. In contrast to public banking issues [6], parental attitudes to private banking have been currently not well studied [3]. Additionally, it is not clear yet which possible model of hybrid banking is best in the view of the donating parents. It is unclear whether a split model, as proposed recently by the Virgin Health Bank in the UK (80\% of the initial UCB unit stored in the public inventory and $20 \%$ of it for private use), is better than a sequential model in which the whole UCB sample is primarily stored in the private inventory, anonymously registered at the international stem cell registry and released after repeated parental consent in case of a request for allogeneic UCB transplantation [7, 8].

Not all collected UCB samples contain sufficient total nucleated cell (TNC) numbers and are rejected from the public UCB bank without further processing. As an alternative to discarding these units, they could be used for research purposes if the donating mother gives consent. Consent policies vary between a single- or a two-step procedure.

The aim of our study was to evaluate the attitudes of our former public UCB donors with regard to public and private banking, their wishes and fears concerning the release of UCB units for allogeneic transplantation and their opinion regarding the release of UCB units with insufficient TNC for banking for research. We wanted to know if our UCB donors would opt for single-step consent for research donation, or if they would prefer a two-step consent procedure in which the donating mother is informed about the sample rejection, the reason for rejection and separately asked to donate the already collected UCB sample for research purposes.

\section{Materials and methods}

\section{Study population}

The study population comprised parents who donated UCB after delivery of their baby to our public UCB bank. Donor selection procedures, and UCB collection and processing were performed in accordance with the FACT/Netcord International Standards for Cellular Therapy Product Collection, Processing, and Administration and approved by the local ethics committee.

Study design and questionnaire

A standardized multiple choice anonymous questionnaire including 20 items was developed and sent to the most recent 621 donors of our public UCB bank in Basel. The home address given at the time of delivery was used to contact the donating mothers.

They were asked to give general information on the infants' health status, month and year of birth of their last baby and their country of origin. The questionnaire contained items on the satisfaction with our procedures of patient information, informed consent and handling during and after delivery. Furthermore, we asked for the donors' views on private UCB banking and their opinion on the drawbacks and assets of public banks. Other topics were attitudes toward UCB stem cell research in general, best consent procedure (single-step or two-step procedure) and 
the desire to be informed and to re-consent before release of their donated UCB unit for allogeneic transplantation.

Statistical analysis

The results were assessed as descriptive statistics. Calculations were performed using a statistical software (SPSS, Version 14.0, SPSS Inc., Chicago, IL, USA).

\section{Results}

Questionnaire and sociodemographic factors

From the 621 questionnaires, 300 were filled out and returned $(48.3 \%)$. Of the 621 questionnaires, 98 could not be successfully delivered due to unknown postal address $(15.8 \%)$. The remaining questionnaires $(35.9 \%)$ were unanswered and no further information could be obtained to characterize this group of donors. The maximum interval between UCB donation and mailing of the questionnaires was 35 months (median 18, range \pm 10.01 ).

The answered questionnaires were mostly from Swiss donors (56\%); 85 were from western European (28.3\%) and 36 from eastern European donors (12\%). Nine donors stated that they came from a country different from the above-mentioned ones (3\%).

Missing data within the questionnaires were rare, ranging from 0.3 to $3.8 \%$ for the directed questions. As much as $84 \%$ of the open questions remained unanswered.

Sources of information on UCB donation and its importance during pregnancy

In most cases, information on UCB donation was provided by the medical health-care professionals $(53.8 \%)$. This was either the primary care obstetrician $(22.2 \%)$ or the obstetrician in charge of the delivery unit $(31.6 \%)$. As much as $22 \%$ of the women stated that they had more than one source of information, including family, friends and the media. During the antenatal visit or at admission to delivery, 34\% actively asked for the option of cord blood donation. The remaining $66 \%$ were informed of the possibility of UCB donation by their caregiver.

Public versus private banking

Most of the former UCB donors (94.9\%) would again choose to donate UCB to the public bank in their next pregnancy, while $2.4 \%$ would then favor private banking. The remaining $0.6 \%$ would not donate again and $2.1 \%$ were indifferent.
Approximately, 69\% of the UCB donors had heard about private banking as a possible option for their UCB to be stored, whereas $27 \%$ of women stated that they did not know anything about private UCB banking. One-third of the UCB donors $(34.7 \%)$ were primarily convinced about the advantages of the public banks, whereas $34 \%$ discussed the different options with their family and caregivers and finally chose donating to the public bank. Reasons for donating to the public UCB bank were mostly the high costs of private banking combined with the altruistic motive of being able to help people in need through the storage of the UCB unit in the public inventory $(69.4 \%)$. Another $16.9 \%$ also mentioned organizational reasons, i.e., there was not enough time to organize private banking or they had been informed too late or had never discussed this topic during pregnancy. Sixteen percent of women gave detailed information on their particular concerns regarding public UCB banking (Table 1).

Information and option for re-consent before release for allogeneic transplantation

A minority of our UCB donors (34.9\%) stated that information before release of the donated UCB unit for allogeneic transplantation was either not necessary or not important to them. However, $65.1 \%$ would appreciate to be informed about this issue. Most of them (80.9\%), although wishing to be informed, would not opt for re-consent before releasing the sample. Only $19.1 \%$ stated that they would like to have the option for consenting a second time (Fig. 2).

Use of rejected UCB units for stem cell research

There were notable differences in our study population of UCB donors regarding attitudes toward UCB stem cell research (Fig. 3). The majority $(53.5 \%)$ would donate a rejected UCB sample if the particular research project were known and would therefore opt for a two-step consent procedure. In this group, $12.3 \%$ stated that they were concerned about unauthorized use of the UCB sample.

Table 1 Concerns about public UCB banking

\begin{tabular}{ll}
\hline $\begin{array}{l}\text { "Private" access for a sick child or family member is not } \\
\text { possible later }\end{array}$ & $36.7 \%$ \\
No chance to decide again later whether or not to release the & $28.6 \%$ \\
UCB for allogeneic transplantation & $24.5 \%$ \\
No disadvantages seen at all & $4.1 \%$ \\
Complex, time-consuming process (i.e., a lot of paper work) & $4.1 \%$ \\
The actual use of the UCB unit is unknown to the donor & $2 \%$ \\
Concern about unauthorized use for research
\end{tabular}

This open question was answered on 48 of 300 questionnaires 


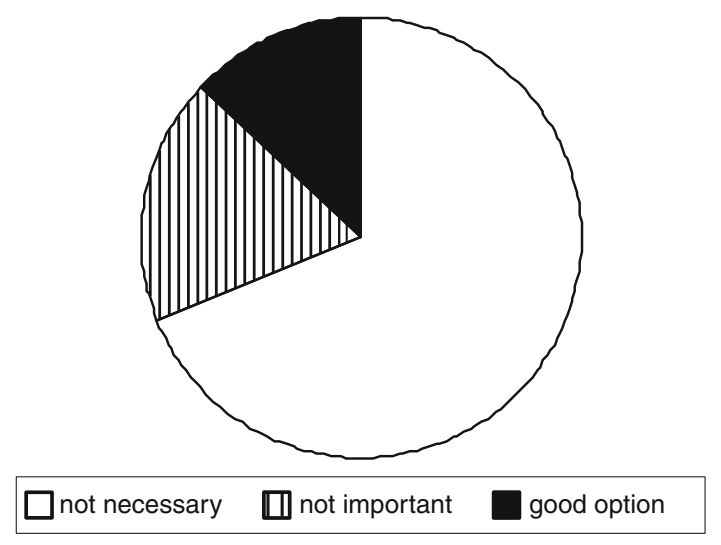

Fig. 2 The importance of a re-consent before final release of the UCB sample for allogeneic transplantation

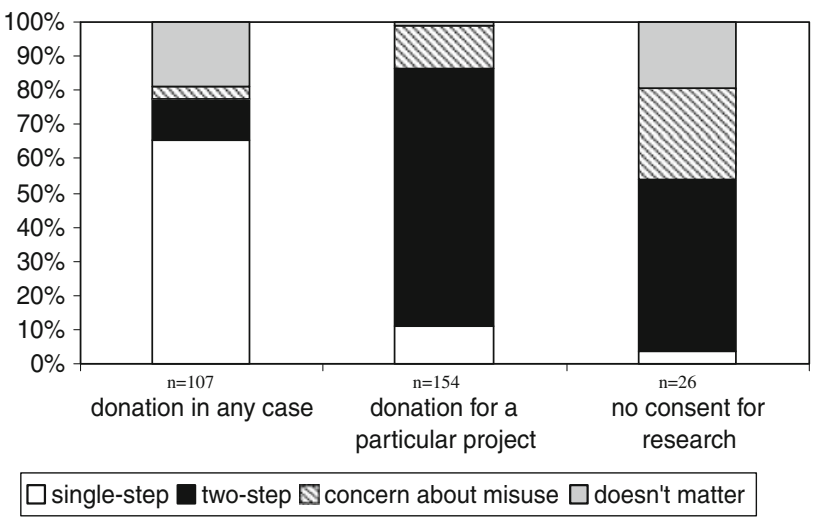

Fig. 3 Different attitudes, concerns and consent procedures before release of a rejected UCB sample for research purposes

About one-third of the UCB donors (37\%) would release their rejected UCB sample in any case for research. In this group, $65.4 \%$ would prefer a single-step consent procedure including both general informed consent on public UCB banking plus release for research in case of sample rejection. Improper use of the UCB sample in research was less of a concern in this group and was mentioned in only $3.7 \%$ of questionnaires. A third group of women ( $9 \%$ of UCB donors) indicated that they would never consent for UCB research. In this group, half would prefer a two-step consent procedure for this reason. Improper use of the UCB sample in research was an issue for $26.9 \%$ of donors in this group.

\section{Discussion}

Public UCB banking for allogeneic stem cell transplantation has become a well-established alternative therapeutic option for quickly providing an HLA-typed, immunologically naïve graft of high proliferative capacity. Since there is extensive evidence showing that UCB-derived transplants are at least of similar efficacy as those obtained from adult peripheral blood or bone marrow even in adults, the need for UCB banking has been on the rise [9]. In contrast, autologous UCB stem cell transplantation with UCB banked in private institutions is currently the exception [10]. Although autologous UCB banking is of more speculative nature primarily concerning possible future application in tissue regeneration, this market is currently growing, whereas allogeneic public UCB banks worldwide struggle for public funding. In this context, a combination of private and public UCB banking would be ideal if quality and safety standards were equal. The quality of UCB units from private banks, however, is not well studied and one recent publication on this topic showed that all quality parameters (volume, $\mathrm{CD}$ 34 count, TNC count) were substantially inferior in the UCB units from the private bank compared to UCB from the public bank [11].

Additionally, little is known whether such a combination at all would be an option for the current public UCB donors.

Informing expectant parents of the possibility of UCB banking is increasingly becoming a part of routine pregnancy visits. Information on this topic needs to be balanced and accurate, and provide sufficient information on both the advantages and disadvantages of the two currently different storage options [12]. This is a challenging task, especially if cord blood banking is discussed shortly before birth or even after the due date. Additionally, there is a growing need for stem cells for research purposes [13]. In our study, most donors received information during pregnancy, mostly from a health-care professional. Although the media, family and friends do play a role since public interest in UCB donation is growing, the fact that healthcare professionals addressed the UCB donation in $60 \%$ of the cases shows how important the role of the obstetrician or primary caregiver is. This is supported by other studies, which show that doctors need to address the topic and need to guide the expectant couple in the decision-making process to ensure the receipt of balanced and good quality information $[14,15]$. Based on our data, public UCB banks would miss more than half of their donors if couples were not actively asked for UCB donation by the physician.

As far as the options of autologous versus allogeneic UCB donation is concerned, private banking is not popular among our public banking donors. More than $90 \%$ of the former public UCB donors would choose public banking in their next pregnancy. The donors realize the current financial barriers of private banking and acknowledge the public good of allogeneic UCB banking. We therefore speculate that combining public and private banking into a hybrid banking model requiring some personal financial 
investment would rather lead to fewer UCB donors from the population, considering that a third of them are of immigrant background with most probably limited financial resources [4].

About one-third of donors stated that they had never heard of private banking. This might be those who were admitted to our unit very soon before delivery when obstetrical care had priority and the two options could not be discussed in any detail. It is not clear whether in this situation it would be feasible to explain all issues on hybrid UCB banking in order for the expectant parents to make an informed decision.

Donors stated that they would appreciate information if their donated UCB unit was released for transplantation for personal reasons, but would prefer not to interfere in this process through a re-consent. Two-thirds of the donors stated that the motivation to donate UCB would not be improved had there been an option to decide on the release of the UCB for transplantation at a later time. Practically, it seems to be difficult to contact a relevant proportion of the public donors for follow-up, even after a relatively short time period, due to migration. It is therefore difficult to imagine that a sequential hybrid banking model would work in our area. This also brings up one major disadvantage of this model, which is the increased delay between transplant request and actual transplantation, should it be necessary to find former UCB donors for a reconsent. The other model of hybrid UCB banking is split hybrid banking. Here, $20 \%$ of the UCB volume is stored in a private bank and $80 \%$ of the volume is donated to a public bank. Although a re-consent is not necessary in this type of banking, there is another major problem: the TNC count of each individual UCB unit for the public bank is reduced by approximately $20 \%$. Since a low TNC count is one of the most relevant problems in cord blood transplantation in general, the split model is less likely to have success from a medical point of view. So far, the only cord blood bank providing this concept is the Virgin Health Bank in the UK and the results from their bank have not yet been published.

Over $90 \%$ of the public donors accept and support stem cell research. In case of sample rejection for clinical use, most of the donors would agree to release their unit for research experiments. However, only $30 \%$ would accept a general consent at the time of UCB donation. More than half of the donors wanted to know the exact study and field of research. Based on our data, a single-step consent procedure for both UCB donation to the public bank and research cannot be supported. It remains difficult to find an optimal way to recruit sufficient donors for research. As much as $57 \%$ of the rejected UCB units could be used for a particular research project. Since our current two-step consent procedure is time-consuming, in most of the cases the sample finally is older then $24 \mathrm{~h}$ at the time of consent and therefore is also no longer suitable for research (data not shown). Although the general consent would reduce the administrative costs and make the UCB units available for research more rapidly, it might be unethical. As an alternative, one could primarily offer UCB donation for research instead of donation to the UCB bank in cases where the banking rates are known to be low, for example, in elective cesarean sections [16].

One of the major limitations of our study was that only donors whose UCB units were finally stored were included. This design was chosen because we specifically wanted to study the attitudes, toward hybrid banking, of those who had previously been involved in UCB donation. It would be, however, worthwhile to study these attitudes in an unselected population of pregnant women.

In conclusion, public banking donors appear to be a well-informed group of people who take an interest in UCB banking and support research in case of rejection from the public UCB bank. Although the rights to the UCB unit are transferred to the UCB bank upon donation, the parents would appreciate information on release for transplantation, as well as on release for research purposes in case of clinical sample rejection. For practical reasons, a split hybrid banking model would be most feasible when considering implementation of hybrid banking. However, the motivation in favor of private banking is low. We conclude from our results that hybrid banking would not be well supported by the current UCB donors. It can even be speculated that the introduction of such a model as the only type of UCB banking might lead to the loss of a relevant proportion of the target group of mostly immigrant donors from ethnic minorities with rare HLA alleles, since the personal financial contribution would probably act as a determent to donation.

Acknowledgments The Basel cord blood bank is supported by the Swiss Foundation "Swiss Blood Stem Cells". We thank Dorothy Huang for critically reviewing the manuscript.

Conflict of interest None.

\section{References}

1. Sullivan MJ (2008) Banking on cord blood stem cells. Nat Rev Cancer 8:555-563

2. Troeger C, Meyer-Monard S, Tichelli A, Manegold G, Pauli D, Surbek D, Holzgreve W, Bürki N (2007) Problems in umbilical cord blood collection. Transfus Med Therapy 34:95-98

3. Fisk NM, Roberts IA, Markwald R, Mironov V (2005) Can routine commercial cord blood banking be scientifically and ethically justified? PLoS Med 2:e44

4. Meyer-Monard S, Passweg J, Troeger C, Eberhard HP, Roosnek E, de Faveri GN, Chalandon Y, Rovo A, Kindler V, Irion O, 
Holzgreve W, Gratwohl A, Müller C, Tichelli A, Tiercy JM (2009) Cord blood banks collect units with different HLA alleles and haplotypes to volunteer donor banks: a comparative report from Swiss blood stem cells. Bone Marrow Transplant 43(10):771-778

5. Hayani A, Lampeter E, Viswanatha D, Morgan D, Salvi SN (2007) First report of autologous cord blood transplantation in the treatment of a child with leukemia. Pediatrics 119:296-300

6. Danzer E, Holzgreve W, Troeger C, Kostka U, Steimann S, Bitzer J, Gratwohl A, Tichelli A, Seelmann K, Surbek DV (2003) Attitudes of Swiss mothers toward unrelated umbilical cord blood banking 6 months after donation. Transfusion 43:604-608

7. Anonymous (2007) Umbilical cord blood banking Richard Branson's way. Lancet 369:437

8. http://www.vita34.de/vita/de/zusatzoptionen.php?navanchor=211 0002. Accessed 20 February 2009

9. Sauter C, Barker JN (2008) Unrelated donor umbilical cord blood transplantation for the treatment of hematologic malignancies. Curr Opin Hematol 15:568-575

10. Samuel GN, Kerridge IH, O'Brien TA (2008) Umbilical cord blood banking: public good or private benefit? Med J Aust 188:533-535
11. Sun J, Allison J, McLaughlin C, Sledge L, Waters-Pick B, Wease S, Kurtzberg J (2010) Differences in quality between privately and publicly banked umbilical cord blood units: a pilot study of autologous cord blood infusion in children with acquired autologous disorders. Transfusion [Epub ahead of print]

12. ACOG Committee Opinion Number 399 (2008) Umbilical cord blood banking. Obstet Gynecol 111:475-477

13. Jacobs VR, Niemeyer M, Gottschalk N, Schneider KT, Kiechle M (2005) Private umbilical cord blood banking does not reduce the number of samples for scientific stem cell research. Z Geburtshilfe Neonatol 209:223-227

14. Fox NS, Stevens C, Ciubotariu R, Rubinstein P, McCullough LB, Chervenak FA (2007) Umbilical cord blood collection: do patients really understand? J Perinat Med 35:314-321

15. Perlow JH (2006) Umbilical cord blood banking options and the prenatal patient: an obstetrician's perspective. Stem Cell Rev 2:127-132

16. Manegold G, Meyer-Monard S, Tichelli A, Pauli D, Holzgreve W, Troeger C (2008) Cesarean section due to fetal distress increases the number of stem cells in umbilical cord blood. Transfusion 48(5):871-876 